\title{
A morte e o morrer segundo representações de estudantes de enfermagem*
}

\author{
DEATH AND DYING ACCORDING TO NURSING STUDENTS' REPRESENTATIONS \\ LA MUERTE Y EL MORIR SEGÚN REPRESENTACIONES DE ESTUDIANTES DE ENFERMERÍA
}

José Rodrigo de Oliveira ${ }^{1}$, José Roberto da Silva Brêtas ${ }^{2}$, Lie Yamaguti ${ }^{3}$

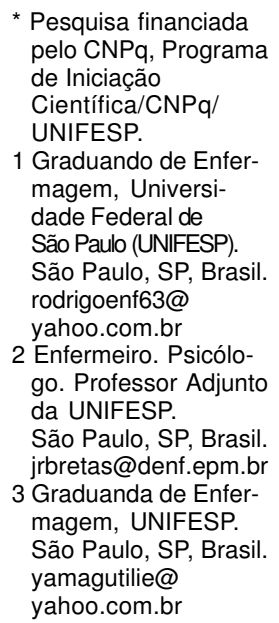

* Pesquisa financiada pelo CNPq, Programa de Iniciação Científica/CNPq UNIFESP.

1 Graduando de Enfermagem, Universidade Federal de São Paulo (UNIFESP). São Paulo, SP, Brasil. rodrigoenf63@ yahoo.com.br 2 Enfermeiro. Psicólogo. Professor Adjunto da UNIFESP

São Paulo, SP, Brasil. jrbretas@denf.epm.br 3 Graduanda de Enfermagem, UNIFESP.

São Paulo, SP, Brasil. yamagutilie@ yahoo.com.br

\section{RESUMO}

Trata-se de um estudo qualitativo, cujo objetivo foi conhecer as representações das estudantes do curso de graduação em Enfermagem da Universidade Federal de São Paulo, sobre as questões que envolvem a morte e o morrer. Os sujeitos foram 40 estudantes do sexo masculino e feminino que freqüentavam a $2 .^{a}, 3 .^{a}$ e $4 .^{a}$ séries do curso de graduação em Enfermagem. Como metodologia, foram utilizadas as premissas das Representações Sociais, usando a técnica de entrevista com duas questões norteadoras não estruturadas. Os resultados deste estudo foram organizados e dispostos em uma árvore máxima, tendo como núcleo central da representação o evento morte e como representações periféricas mais importantes: conceitos, medo da morte e relacionamento aluno-paciente.

\section{DESCRITORES}

Estudantes de enfermagem.

Morte.

Saúde mental.

Tanatologia.

\section{ABSTRACT}

This is a qualitative study whose objective was to know the representations of the Federal University of São Paulo's undergraduate Nursing students on the questions that involve death and dying. The subjects were 40 students, males and females, in the $2^{\text {nd }}, 3^{\text {rd }}$ and $4^{\text {th }}$ year of the undergraduate course in Nursing. As a methodology were used the assumptions of the Social Representations, using the technique of an interview with two nonstructured guiding questions. The results of this study were organized and placed on a maximum tree having as the representation's central nucleus the event death and as the most important peripheral representations concepts, fear of death and relationship pupil-patient.

\section{KEY WORDS}

Students, nursing.

Death.

Mental health.

Thanatology.

\section{RESUMEN}

Se trata de un estudio cualitativo, cuyo objetivo fue conocer las representaciones de los estudiantes del curso de graduación en Enfermería de la Universidad Federal de São Paulo, sobre las cuestiones que envuelven la muerte y el morir. Los sujetos fueron 40 estudiantes del sexo masculino $\mathrm{y}$ femenino que frecuentaban la $2^{\mathrm{a}}, 3^{\mathrm{a}}$ y $4^{\mathrm{a}}$ series del curso de graduación en Enfermería. Como metodología usamos las premisas de las Representaciones Sociales, utilizando la técnica de entrevista con dos cuestiones dirigidas no estructuradas. Los resultados de este estudio fueron organizados y dispuestos en un árbol máximo, teniendo como núcleo céntrico de la representación el evento muerte y como representaciones periféricas más importantes: conceptos, miedo a la muerte y relación alumno-paciente.

\section{DESCRIPTORES}

Estudiantes de enfermería.

Muerte.

Salud mental.

Tanatología. 


\section{INTRODUÇÃO}

No ambiente hospitalar o cuidar envolve, verdadeiramente, uma ação interativa. $O$ processo de cuidar é definido como o desenvolvimento de ações, atitudes e comportamentos com base em conhecimento científico, experiência, intuição e pensamento crítico realizado para e com o cliente, cuidado no sentido de promover, manter e/ou recuperar sua dignidade e totalidade humana. O termo cuidado em enfermagem tem sido utilizado para denotar um serviço oferecido por enfermeiros àqueles que apresentam necessidades relacionadas ao binômio saúde-doença. A distinção entre as polaridades de compreensão sobre o cuidado de enfermagem, que se refere ao desempenho de procedimentos específicos por parte das enfermeiras, e a expressão cuidar em Enfermagem denota a totalidade de serviços prestados através das interações enfermeiro-paciente ${ }^{(1)}$.

Durante o exercício da profissão, os enfermeiros seguem normas e condutas objetivando salvar vidas e evitar a morte, que, quando se faz presente, pode causar um estado de tristeza, perda, frustração e estresse já que ver o corpo inerte de uma pessoa para o qual se prestou cuidados, se dedicou tempo, energia, carinho, amor, se trocou palavras e até mesmo se riu lado a lado é algo que causa estranheza ${ }^{(2)}$. A partir desta questão e tendo como referencial a formação do ser enfermeiro, que ocorre durante a graduação, surge a seguinte pergunta: Os estudantes de enfermagem estão recebendo preparo adequado para o enfrentamento do processo doença-morte no convívio hospitalar?

Os estudantes de enfermagem são treinados para desenvolver uma relação com o paciente segundo os modelos descritos nos livros de enfermagem. Aprendem que o cuidar é um dos ingredientes essenciais da vida; que o cuidar ajuda a assegurar que a vida continue, pela construção de um ambiente propício para crianças e adultos. O cuidar ajuda a evitar doenças, a promover a saúde, curar ou ajudar os vulneráveis, educar a população e elevar as relações humanas a experiências gratificantes de prazer, segurança, confiança, crescimento e atividade produtiva. Amor, ódio, medo, felicidade, raiva, prazer, ou qualquer outra emoção humana podem receber os efeitos produtores de crescimento, geradores de energia, motivadores e, consistentemente, positivos do cuidar. Todos os demais sentimentos humanos possuem efeitos potencialmente negativos, bem como positivos, mas o cuidar, por sua natureza e definição, é somente e sempre positivo.

A problematização deste estudo resumiu-se da seguinte forma: como o estudante sente, percebe e organiza-se diante da possibilidade ou da concretude da morte de um cliente?

Diante desta questão, entendemos a importância deste estudo para obtenção de algumas respostas, com a finalida- de de identificar se os estudantes do curso de enfermagem estão sendo preparados para manutenção da vida, como também para o processo doença-morte.

A finalidade deste estudo caracterizou-se por coletar elementos para elaboração de uma disciplina eletiva que possibilite a reflexão e discussão sobre o tema morte e o morrer, visando buscar caminhos para que os futuros profissionais de enfermagem possam lidar com a morte no seu ambiente de trabalho, segundo uma postura profissional e essencialmente humana. Teve por objetivo conhecer e identificar as representações dos estudantes do curso de graduação em Enfermagem da Universidade Federal de São Paulo, frente às questões que envolvem a morte e o morrer.

\section{MÉTODO}

Trata-se de um estudo com abordagem qualitativa, para o qual utilizamos as premissas das Representações Sociais, tendo como referencial de análise os estudos realizados ${ }^{(3-5)}$.

Por representações sociais entendemos um conjunto de conceitos, proposições e explicações originadas na vida cotidiana no curso de comunicações interpessoais. Elas são o equivalente, em nossa sociedade, aos mitos e sistemas de crença das sociedades tradicionais; podem também ser vistas como a versão contemporânea do senso comum $^{(6)}$. É uma forma de conhecimento socialmente elaborada e partilhada, tendo uma visão prática e concorrendo para a construção de uma realidade comum a um conjunto social ${ }^{(7)}$.

Esta pesquisa teve seu projeto (CEP n ${ }^{\circ} 0972 / 03$ ) avaliado e aprovado pelo Comitê de Ética da Universidade Federal de São Paulo. Todos os procedimentos metodológicos obedeceram aos padrões estabelecidos pela Resolução 196/ 96, que trata das Normas de Pesquisa Envolvendo Seres Humanos ${ }^{(8)}$. Foi realizada na Universidade Federal de São Paulo junto a estudantes do curso de graduação de Enfermagem. Os sujeitos desta pesquisa foram constituíram-se de 40 estudantes do sexo masculino e feminino escolhidos aleatoriamente. Optamos por entrevistar estudantes do $2^{\circ}, 3^{\circ}$ e $4^{\circ}$ anos que apresentavam vivências em estágios curriculares. Do total das entrevistas, 15 estudantes (38\%) eram do $4^{\circ}$ ano, $15(38 \%)$ do $3^{\circ}$ ano e $10(24 \%)$ do $2^{\circ}$ ano; a média de idade entre as estudantes foi de 23 anos, sendo que a idade mínima foi de 19 anos e a máxima de 48 anos.

Para a coleta de dados, utilizamos como instrumento a entrevista individual em local reservado, a qual possibilita uma atmosfera de interação e reciprocidade entre quem entrevista e o entrevistado ${ }^{(9)}$. As entrevistas foram gravadas apenas após a aquiescência dos estudantes, e posteriormente transcritas pelo entrevistador, de forma sigilosa, garantido aos mesmos o anonimato. 
Para nortear a entrevista, elaboramos algumas proposições ou questões orientadoras da investigação, que se constituiu de: 1 . O que é a morte para você?; 2 . como você encara ou espera encarar a morte no ambiente de trabalho?

Após a realização das entrevistas utilizamos a técnica de análise do discurso, na qual o trabalho de interpretação seguiu os seguintes passos: leitura flutuante do material; transcrição do material; elaboração de mapa dos temas emergentes; construção do discurso; transporte das associações para um gráfico, pontuação das relações entre elementos cognitivos, práticas e investimentos afetivos.

\section{ANÁLISE DOS DADOS}

Após a transcrição do material, elaboramos um mapa contendo os temas emergentes, no qual pontuamos o núcleo central que representa a morte. Ligados a este núcleo central estão os elementos periféricos, como podemos observar na Figura 1.

Como núcleo central temos o episódio da morte. Quanto ao sistema periférico, este se constitui por três principais ramos de representações, desvelados pelos sujeitos, que são: conceitos, o medo da morte e o relacionamento alunopaciente.

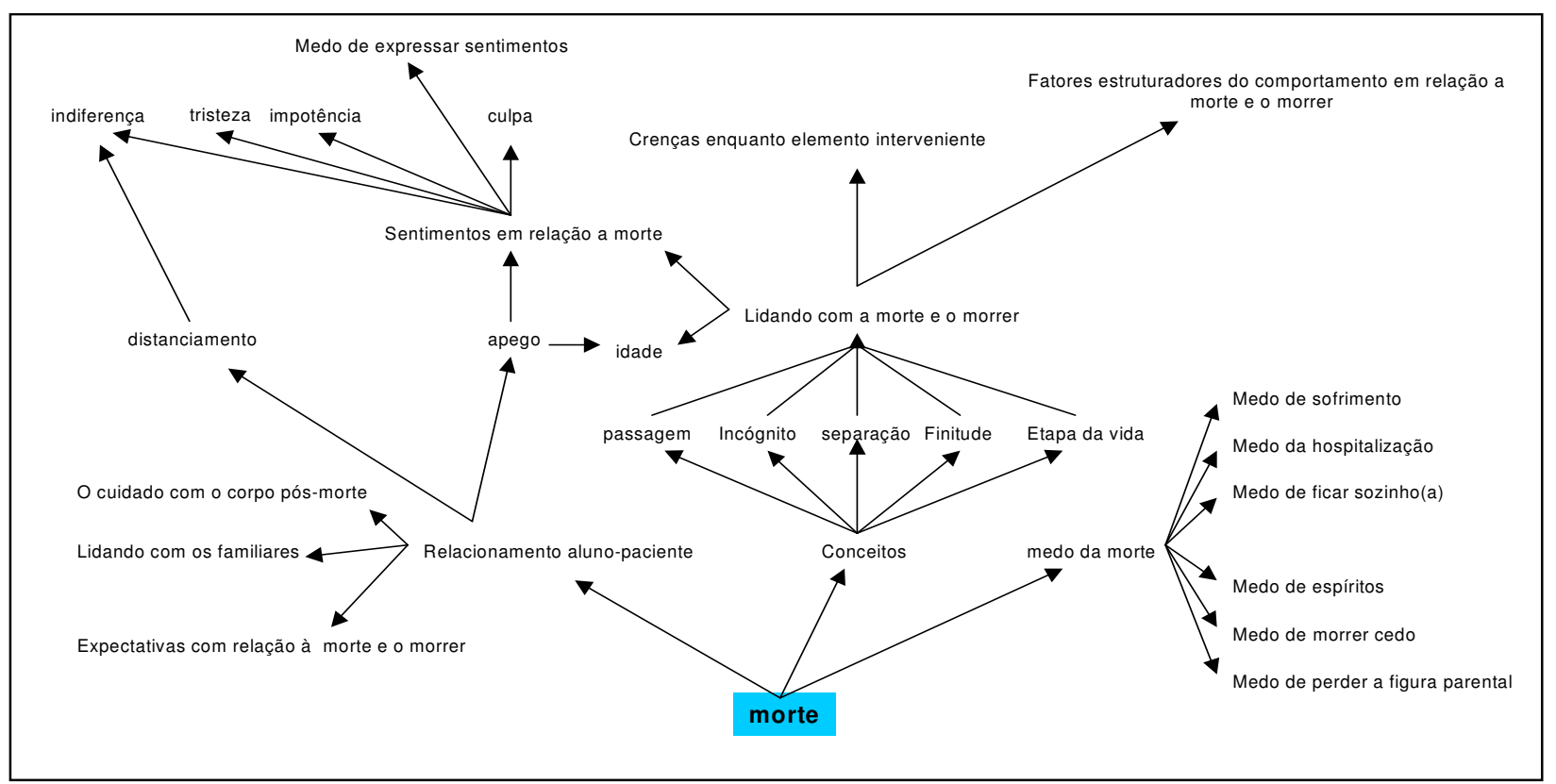

Figura 1 - Árvore Máxima da Representação Social dos estudantes de Enfermagem sobre a morte e o morrer - São Paulo - 2005

A representação de conceitos desmembra-se em elementos como: passagem, incógnita, separação, finitude e etapa da vida. O elemento denominado passagem compreende uma concepção espiritual do tema central, segundo a qual a pessoa tem a morte enquanto transição entre o mundo material e o espiritual. Como exemplo destacamos os seguintes recortes de falas dos estudantes:

\section{Eu acho que é uma passagem, uma etapa da vida, eu acho que o nosso corpo fica e nosso espírito vai para outro lugar.(E-1)}

Neste sentido, a morte como transição é a representação das crenças e convicções espirituais do ser humano ${ }^{(5)}$. É vista como evento que ocorre com todos, num futuro, portanto supostamente desconhecido. Entretanto, alguns relatos apresentam, com tanta convicção, uma visão do que vai acontecer depois, que parecem supor um conhecimento que contrasta com o (des) conhecimento que envolve a morte.
Quanto ao elemento denominado incógnito, interpretamos como aquilo que é desconhecido, enigmático, como observamos na frase a seguir:

É uma coisa desconhecida para mim, não sei o que é verdade, então eu ignoro, então, o que tiver que ser, será. (E-9)

A morte vista como o desconhecido traz à tona a emoção do medo, o mistério, o não familiar, que, é também associada a um certo fascínio, de que o desconhecido oferece a possibilidade de descobrir algo que não se conhece e que pode ser mais instigante que a própria existência ${ }^{(5)}$.

O elemento separação nos mostra o afastamento de pessoas com vínculos afetivos entre si, caracterizando um acontecimento sem volta, permeado de saudosismo, como podemos observar na fala:

Para mim, morte é a separação, de você ficar longe das pessoas queridas. (E-4) 
A perda de uma pessoa amada é uma das experiências mais intensamente dolorosa que o ser humano pode sofrer. É penosa não só para quem experencia, como também para quem a observa, ainda pelo fato de sermos tão impotentes para ajudar ${ }^{(10)}$. O elemento finitude revela o caráter de finito, ou seja, que tudo está acabado. Neste caso, temos a desvinculação do tema morte ao aspecto religioso/espiritual, denotando uma visão de cunho materialista.

Morte é o fim de tudo, é o fim de tudo que você fez, tudo que você cultivou. (E-5)

A morte ligada à idéia de finitude pode vir acompanhada de tristeza e revolta. Considerando que interrompe a vida, podendo-se pensar na morte fora de hora. Pode também ser encarada com indiferença, fatalidade, após ter-se cumprido uma missão; poderá ser chamada de morte na hora $\operatorname{certa}^{(4)}$.

O elemento etapa da vida nos desvela a compreensão da morte enquanto um processo natural, relacionado ao desenvolvimento do ser humano.

Morte é o fim da manifestação da vida de uma pessoa. É um acontecimento biológico, alias é um acontecimento que faz parte da vida, meio estranho falar que faz parte da vida, mas[...]. (E-19)

Nessa representação, a morte é decorrência e faz parte da vida, despersonalizada, não é de ninguém, é de toda humanidade. Vista como evento natural, as pessoas se tornam observadoras do seu processo de morrer ${ }^{(5)}$. Desta forma, esta conexão entre vida e morte aparece também quando se afirma que a morte está no cotidiano das pessoas.

Todos os elementos descritos (passagem, incógnito, separação, finitude e etapa da vida) convergem para a representação denominada de lidando com a morte e o morrer. Trata-se da descrição de formas adotadas para enfrentar situações que envolvam a morte e o morrer, como observamos nas frases:

Eu acredito que tem vida após a morte, você já cumpriu seu papel aqui na terra e acaba passando para outro plano, só de pensar assim me sinto confortada. (E-2)

Às vezes a pessoa está sofrendo tanto, que até a morte seria melhor para pessoa, descansar em paz como falam por aí. (E-12)

Um autor ${ }^{(11)}$ refere que se negamos a morte, se nos recusarmos a entrar em contato com nossos sentimentos, esse luto será mal elaborado e, assim, teremos uma chance maior de adoecermos, cairmos em melancolia e em outros processos substutivos.

Negar a morte é uma das formas de não entrar em contato com experiências dolorosas. A grande dádiva da negação e da repressão é permitir que se viva num mundo de fantasia, no qual há ilusão de imortalidade. O mesmo autor afirma que negar a morte pode dar idéia de força e controle; entretanto, uma perda seguida de precária ou má elaboração do luto - não se permitindo a expressão da tristeza e da dor tem trazido graves conseqüências como a maior possibilidade de adoecimento ${ }^{(11)}$.

A partir desta representação, desvelamos elementos como: crenças enquanto elemento interveniente e fatores estruturadores do comportamento em relação à morte e o morrer.

Com relação à crenças enquanto elemento interveniente entendemos tratar-se de um objeto de crença, uma conviç̧ão íntima em que a fé religiosa influencia a capacidade de enfrentamento de situações envolvendo a morte e o morrer, como podemos observar nas falas dos estudantes:

Ter uma convicção por uma coisa que você não vê, que não pode sentir fisicamente, sei o que vai acontecer comigo, eu tenho essa certeza pela fé. (E-24)

A única certeza que a gente tem é que vai morrer, mas na religião, a filosofia que tenho é espiritual, então a morte não é o fim, não vejo a morte como algo ruim, só que eu tenho medo [...]. (E-24)

Esta representação da morte como limite nos ajuda a crescer, mas a morte vivenciada como limite, também é dor, perda da função, das carnes, do afeto. O papel da religião é, em parte, o de socializar e dirigir os ritos de morte como forma de lidar com o terror ${ }^{(3)}$.

Por outro lado, os ritos destinados aos mortos sempre estiveram vinculados ao medo de que eles pudessem importunar e aterrorizar os vivos ${ }^{(3)}$.

Quanto aos fatores estruturadores do comportamento em relação à morte e o morrer, revelamos elementos que contribuem com a ordem das atitudes frente à temática, que podem ser representadas por:

Eu acho que o pior é o sofrimento antes da morte, a gente fica pensando o que pode acontecer para quem está morrendo. (E-26)

Eu penso assim, se você morrer, acabou, mas o pior é quando morre alguém que você gosta porque fica a lembrança da pessoa. (E-32)

Outro ramo de representação importante é medo da morte, que se decompôs em: medo do sofrimento, medo da hospitalização, medo de ficar sozinho, medo de espiritos, medo de morrer cedo, medo de perder a figura parental.

O medo é a resposta psicológica mais comum diante da morte. $\mathrm{O}$ medo de morrer é universal e atinge todos os seres humanos, independente da idade, sexo, nível socioeconômico e credo religioso ${ }^{(3)}$.

A gente ouve todo mundo falar que geralmente todos profissionais fogem nessa hora. A pessoa e o familiar acabam ficando sozinhos e eu não quero isso; então quero me preparar para poder dar apoio para as pessoas que venham perder alguém. (E-3) 
O medo do sofrimento caracteriza-se pelo temor de passar por procedimentos invasivos, incapacitantes e pela perda do controle sobre si, em um período que antecede a morte:

[...] acho que é algo do psicológico do ser humano, de querer se defender daquilo que ele não suportaria; então, para muitas pessoas, a morte é uma coisa insuportável. Tem gente que só pensar em morrer já não quer falar sobre o assunto, acho que as pessoas ficam com medo de viver outras coisas, de reviver parentes que já faleceram. (E-4)

O mais comum de todos os medos é que a morte seja dolorosa. A frase morreu em agonia parece estar gravada nas mentes das pessoas, motivando uma expectativa mal fundamentada em relação à morte ${ }^{(12)}$.

O medo da hospitalização desvela o receio que o indivíduo tem de não poder retornar ao seu lar, permanecendo no ambiente hospitalar, longe de seus familiares e pertences, como observamos na frase:

[...] então, o hospital já tem um estereótipo de ser uma coisa ruim e, às vezes, que leva a morte, às vezes a pessoa estava bem em casa vai para o hospital e piora por causa dos problemas. (E-7)

O medo de ficar sozinho(a), relaciona-se diretamente com o item anterior, evidenciado pelo temor de ficar sozinho(a), hospitalizado em um lugar estranho, cuidado por desconhecidos; o fato preponderante deste contexto é a possibilidade de morrer sozinho, junto a estranhos:

Eu não sei, tenho medo de ficar sem a pessoa ou então medo de ir embora e deixar a pessoa sem mim, não sei de onde surgiu esse medo. É mais um medo de ficar sozinha. (E-33)

$\mathrm{O}$ medo de espíritos diz respeito a fenômenos sobrenaturais, com base nas crenças religiosas e crendices populares:

Eu tenho medo de espíritos, de alguém que eu conheço aparecer [...]. (E-36)

A sensação de que o morto está presente é comum nos primeiros estágios do pesar e pode ser considerada como uma tentativa da psique para mitigar a sensação de perda ${ }^{(12)}$.

$\mathrm{O}$ medo de morrer cedo está relacionado à interrupção prematura da existência humana, ou seja, deixar de viver antes da concretização de um determinado projeto de vida, como observamos na fala que segue:

Tenho medo de morrer e de não viver tudo que eu espero viver, de fazer varias coisas assim que eu espero fazer. (E-35)

$\mathrm{O}$ medo de perder a figura parental enfoca a preocupação com a morte do outro, como encontramos nas falas que seguem:
A morte é uma coisa ruim, acho que para todo mundo. Tenho medo da morte, tenho medo de deixar meus parentes, tenho medo de deixar principalmente a minha mãe, fico meio preocupado e tenho medo de eu morrer. (E-4)

Quanto ao medo da perda, a teoria da fixação, derivada com estudo feito com animais e bebês, mostra como a ameaça da separação da figura parental provoca ansiedade e estimula, no paciente, o impulso primitivo de apegar-se a esta figura $^{(12)}$.

A morte como perda é a morte do outro internalizada. Faz parte da vida e, dificilmente, não terá sido vivida pelas pessoas. Há uma subdivisão entre a morte concreta, aquela que ocorre efetivamente, ou seja, a morte da pessoa com quem se mantém um vinculo e, a simbólica, quando se referem a perdas não resultantes de morte, como a separação, perda de um emprego etc ${ }^{(4)}$.

O terceiro principal ramo de representação enfoca $o$ relacionamento aluno-paciente, na qual emergem elementos como: expectativas com relação à morte e o morrer, lidando com os familiares, o cuidado com o corpo, distanciamento e apego.

$\mathrm{Na}$ relação aluno-paciente destacamos as seguintes frases:

Para ter uma melhor relação com o paciente, para que ele possa confiar em você, sentir-se mais à vontade, ter mais intimidade, tem que ter envolvimento. (E-1)

Tem pessoas que falam que se apegam complemente, e pessoas que não se apegam, assim como tem pessoas que se afastam. Acredito que durante a estada com o paciente em tratamento você acaba tendo um grau de envolvimento. (E-10)

Quanto à expectativas com relação à morte e o morrer, as representações nos mostraram a existência de expectativas, resultantes do contato do estudante de Enfermagem com a possibilidade da morte e o morrer no ambiente em que desenvolve procedimentos práticos e vivencia sua relação com o cliente, assim descritas:

Espero encarar muito bem. Eu acho que lidar com a morte é muito complicado, por mais que não tenha uma ligação com a pessoa, ainda tem aquela coisa de que a pessoa morreu. $(E-1)$

Eu nunca tive que encarar a morte de um paciente, mas eu espero encarar assim, vai ser muito difícil e acho que vai ser impossível para não envolver-me e ficar emocionada. (E-3)

Entre as várias formas sob as quais se evidencia a negação da morte no contexto hospitalar, está a questão da linguagem. Na comunicação da equipe, a palavra morte é raramente pronunciada, sendo substituída por outras, como parada cardíaca, por exemplo. A questão central parece 
estar no fato de que a morte no ambiente hospitalar é identificada como fracasso da instituição e do profissional ${ }^{(13)}$.

A morte é, de certa forma, associada à velhice avançada, quando a pessoa já cumpriu uma jornada e estaria "pronta" para morrer ${ }^{(14)}$. A velhice é a fase do desenvolvimento humano que carrega mais estigmas e atributos negativos ${ }^{(3)}$.

A morte como perda nos fala, em primeiro lugar, de um vinculo que se rompe, de forma irreversível, sobretudo quando ocorre perda real e concreta ${ }^{(3)}$.

O item lidando com os familiares mostra a preocupação e dificuldade que o estudante de enfermagem enfrenta ao relacionar-se com os familiares de quem morreu, como observamos nos relatos:

Naquele momento o que importa é a família no global, você como profissional enfermeiro não esta ali só cuidando do paciente, você esta cuidando da família também. (E-4)

A família vai ficar mais desamparada ainda com o momento porque já passa por um momento difícil e você não pode se desesperar deve agir da maneira mais formal. (E-12)

A enfermagem acaba também por ter contato mais próximo com os familiares que estão vivendo situações de ansiedade e desespero diante do sofrimento e da possível perda de seu familiar; buscam respostas, querem confirmação de sua esperança de cura do paciente, sobrecarregando a equipe que tem que dar conta de um número muito grande de atividades. Mas, para o profissional, o que é ainda mais grave é não saber qual é a real situação do paciente, ou, se sabe, sente-se constrangido em dar más notícias, referentes à piora do quadro ${ }^{(5)}$.

O enfermeiro, lidando com esses diversos sentimentos vividos pelos pacientes e familiares pela aproximação da morte, está diante do conflito de como se posicionar frente ao sofrimento e à dor, que nem sempre pode aliviar, tendo também de elaborar perdas de pacientes, principalmente daqueles com quem estabeleceu vínculos mais intensos ${ }^{(5)}$.

Quando membros da família são ouvidos e orientados, podem manifestar um comportamento mais tranqüilo. Infelizmente, não é isto que vem ocorrendo no dia-a-dia das unidades, pois a família, na maioria das vezes, não tem recebido uma assistência de enfermagem que contemple suas necessidades $^{(15)}$.

A representação o cuidado com o corpo pós-morte desvela o impacto causado em estudantes de Enfermagem durante procedimentos que envolvem o cuidado com o corpo do ser humano após o falecimento, como podemos notar nas frases selecionadas:

Nunca tinha visto preparação de corpo nenhum, nem sabia que era feito daquela forma, eu passei mal, chorei [...]. (E-20)
O preparo do corpo pós-morte é uma atribuição que faz parte do cotidiano, da qual é impossível fugir, mesmo quando verbalizado como sendo normal, pois é continuidade dos procedimentos de enfermagem ${ }^{(16)}$. O envolvimento com o paciente é um fator considerável na manifestação do sentimento presente nesse momento, reconhecendo, mais incisivamente, o processo de identificar-se com essa situação, dependendo do vínculo desenvolvido durante o processo do cuidar.

Em um estudo realizado junto à equipe de enfermagem atuante em uma Unidade de Terapia Intensiva, as autoras verificaram que a emoção presente no momento do preparo do corpo é identificada como triste, deprimente, impressionante, fim de luta e sofrimento, estressante e angustiante, chato, além de um mal necessário ${ }^{(16)}$.

O apego desvela o conteúdo afetivo emergente da relação que envolve o ato de cuidar, representado pelas frases:

Fato mais difícil para eu lidar em minha carreira vai ser com relação à morte porque me apego, por mais que eu tente fugir disso. (E-22)

O comportamento de apego é interpretado como qualquer forma de comportamento que resulte na consecução ou conservação, por uma pessoa, da proximidade de alguma outra diferenciada e preferida ${ }^{(10)}$.

No curso de um desenvolvimento sadio, o comportamento de apego leva ao desenvolvimento de laços afetivos ou apegos, inicialmente entre a criança e o progenitor e, mais tarde, entre adulto e adulto. A maioria, se não todos, dos episódios mais intensos de tristeza, é provocada pela perda, ou previsão de perda, seja de uma pessoa amada, de lugares familiares ou de papeis sociais ${ }^{(10)}$.

O item Idade nos revela que é mais fácil a aceitação da morte quando se trata de ser humano adulto ou idoso. Observemos a fala:

Eu acho que encarei bem, por ser uma pessoa mais velha, um senhor que estava sofrendo; se fosse uma criança, um recém nascido, daí eu já não sei como encararia. (E-26)

Entre os agravantes da percepção deste sofrimento, são ressaltados aspectos relativos à faixa etária do paciente: a morte é percebida como mais traumatizante quanto mais jovem for este paciente; muito mais traumatizante ainda, em se tratando de crianças $^{(17)}$.

A proximidade das idades entre quem cuida e quem é cuidado torna a identidade mais imediata e o profissional mais vulnerável ao sofrimento com a possibilidade da morte. Por sua vez, as pessoas idosas têm as suas mortes mais aceitas tanto pelos profissionais como pelos membros da própria família, como uma etapa do ciclo de vida ${ }^{(15)}$. 
Da representação sentimentos em relação à morte emergem alguns elementos que julgamos importantes, que são: indiferença, tristeza, impotência, medo de expressar sentimentos e culpa.

O item indiferença nos mostra um mecanismo de defesa, adotado por muitos estudantes de Enfermagem e enfermeiros, que o utilizam inconscientemente, por vezes conscientemente, buscando, assim, uma autopreservação, ou seja, evitar sentimentos indesejáveis acerca da morte:

Quando tem uma cascata com muito pacientes morrendo, não sei se isto é do ser humano, mas você acaba se acostumando a conviver com aquilo e a conviver com suas emoções. (E-27)

Quanto à Tristeza, entendemos ser um fato normal, fruto do envolvimento emocional que permeia o relacionamento aluno-cliente.

Eu acho que eu ia ficar triste, com sentimento de perda muito grande. (E-2)

O sentimento de Impotência emerge do processo do cuidar, resultado da onipotência, da fantasia de que o conhecimento resolve tudo e da imaturidade, como apresentado na fala abaixo:

Às vezes é uma sensação de impotência porque você não pode fazer nada como profissional, então, eu acho que isso daí é a parte difícil na hora de lidar com a morte. (E-3)

Com relação à impotência, autores ${ }^{(18)}$ afirmam que a morte é percebida pelos profissionais de saúde como um inimigo que contraria seus propósitos de salvar vidas, derrotandoos. A morte é visualizada pelos profissionais como um momento de derrota. Ë como se travassem uma luta imaginária e, quando o paciente morre, significa que perderam a batalha.

Por outro lado, ante a percepção de nossa impotência, por vezes percepção inconsciente, nos defendemos através da onipotência. A certeza de uma vida pós-morte pode ser resultado desse mecanismo. Embora possamos ou não saber que ela existe, o que se observa é que essa certeza decorre da necessidade de enfrentar a impotência, incluindo a impotência do não saber ${ }^{(19)}$.

O medo de expressar sentimentos é resultado da construção do mito de que o Enfermeiro deva ser impassível diante da situação de morte. Diante desta situação, é recomendável que procure não se envolver emocionalmente a ponto de prejudicar o paciente, mas deve ser capaz de rir, chorar ou calar-se, sem esquecer que deve transmitir segurança e desenvolver suas funções.

Eu iria ficar preocupada, será que eu posso chorar na frente do paciente ou eu vou ter que segurar e esconder minhas emoções. (E-7)
No século XX ocorreu uma supressão do luto, escondendo a manifestação ou até mesmo a vivência da dor. Há uma exigência de domínio e controle, pois a sociedade não suporta ver os sinais da morte ${ }^{(4)}$. Por outro lado, não conseguimos evitar ou adiar a morte, ou mesmo aliviarmos o sofrimento, isto pode trazer ao profissional a vivência dos seus limites, impotência e finitude, o que se torna extremamente doloroso $^{(5)}$.

No hospital, ao priorizar salvar o paciente a qualquer custo, a ocorrência da morte ou de uma doença incurável pode fazer com que o trabalho da equipe de saúde seja percebido como frustrante, desmotivador e sem significado. A impotência faz reviver os medos de destruição, vulnerabilidade e separação, possibilitando que o profissional entre em contato com sua própria finitude e mortalidade ${ }^{(5)}$.

Enfermeiros e médicos são submetidos, diariamente, a situações de tensão diante de pacientes hospitalizados. Muitos deles relatam sua impotência e frustração perante a imprevisibilidade da trajetória da morte ${ }^{(4)}$.

É útil usar a expressão luto num sentido amplo, para cobrir uma variedade de reações à perda, inclusive as que levam a um resultado patológico ${ }^{(10)}$. Ver a perda como fatalidade, ocultar os sentimentos, eliminar a dor, apontar o crescimento possível diante dela, podem ser formas de negar os sentimentos que a morte provoca, para evitar o sofrimento ${ }^{(5)}$.

A culpa surge da sua própria formação, segundo a qual os estudantes de Enfermagem são mais preparados para lidar com a vida, deixando à margem ou omitindo os cuidados em relação à morte:

Quando você não consegue cumprir sua função, às vezes, você deve pensar se houve alguma falha, aonde foi a falha, será que a falha foi minha ou se foi conseqüência da patologia? (E-29)

Os profissionais de saúde participam do morrer dos pacientes questionando a sua atuação. Algumas vezes sentem-se culpados, acreditando que falharam na prestação da assistência, pois os profissionais de saúde são preparados para manutenção, preservação e recuperação da vida. Foram treinados para tal. O morrer, nesta conjuntura, emerge como fracasso, ou seja, falharam tecnicamente ${ }^{(18)}$.

Entendemos o distanciamento como um mecanismo de defesa e proteção contra o sofrimento; o processo de morrer e de morte passa a ser visto como banal, sendo o distanciamento e o endurecimento das relações frente à morte $\mathrm{e}$ ao paciente terminal algo tornado natural e considerado comum e rotineiro, como vemos a seguir no relato de um estudante:

Você busca meios de não se envolver tanto com a vida do paciente e busca se conscientizar que todo mundo vai passar por isso; a única certeza que temos é que um dia a gente morre.(E-27) 
$\mathrm{O}$ afastamento do paciente e a delegação de funções podem estar relacionados a problemas de contratransferência diante do indivíduo que está morrendo e a ambivalência entre tentar ainda uma medida heróica e a raiva do fracasso ${ }^{(3)}$.

\section{CONSIDERAÇÕES FINAIS}

A presente pesquisa possibilitou conhecer as representações dos estudantes de enfermagem sobre a morte e o morrer. A análise dos conteúdos enunciados durante as entrevistas possibilitou-nos reconhecer diversos elementos que emergiram através da exploração do tema, sendo pontuados no mapa, o episódio morte como núcleo central e os elementos periféricos que, ligados entre si formaram um sistema que deu sentido a uma representação coletiva.

A partir das representações individuais podemos conhecer os pensamentos, as ações e os sentimentos acerca da morte e do morrer no âmbito coletivo, identificando os conceitos que determinam o comportamento e o enfrentamento, os medos e as crenças.

Percebemos ainda que os estudantes de enfermagem apresentam dificuldades em lidar com o relacionamento aluno-paciente e com os sentimentos que emergem após a morte; referem que o apego pode gerar sentimentos de culpa, impotência, tristeza, medo e indiferença e que o distanciamento poderia amenizar a situação, já que há uma dificuldade em expressar os sentimentos. Outro elemento que merece destaque é a dificuldade que o estudante tem em enfrentar a morte do cliente, assim como os seus familiares.

Com base nas representações, pode-se perceber que existe pouco preparo para lidar com as questões da morte e o

\section{REFERÊNCIAS}

1. Leininger M. Caring: an essential human need: procedings of three nationalcaring conferences. Thorofare, NY: Charles Slack; 1981.

2. Pitta A. Hospital: dor e morte como ofício. São Paulo: Hucitec; 1990.

3. Kovács MJ, Morato HTP, Rothschild D, Freitas LV, Calazans RA, Cassorla RMS, et al. Morte e desenvolvimento humano. São Paulo: Casa do Psicólogo; 2002.

4. Kovács MJ. Pensando a morte e a formação de profissionais de saúde. In: Cassorla RMS, coordenador. Da morte: estudos brasileiros. $2^{a}$ ed. Campinas: Papirus; 1998. p. 79-103.

5. Kovács MJ. Educação para a morte: desafio na formação de profissionais da saúde e educação. São Paulo: Casa do Psicólogo; 2003 .

6. Moscovici S. On social representations. In: Fordas JP. Social cognition: perspectives on everyday understanding. London: Academia Press; 1981. p. 29-64. morrer. O despreparo já se faz sentir na própria bagagem de vida, percorrendo os caminhos da educação, perpetuandose através do curso de formação em enfermagem que ora fazem.

Vemos, de maneira geral, que o estudante de enfermagem ainda está sendo preparado com maior ênfase para lidar com a vida e no que tange aos aspectos técnicos e práticos da função profissional. Há pouca ênfase em questões emocionais e na instrumentalização para o duelo constante entre a vida e a morte, no qual, muitas vezes, deve prestar assistência à pessoa para que tenha uma morte digna.

Achamos que não basta reconhecermos a importância dos atributos e habilidades frente ao processo de cuidar do paciente terminal como se este fosse, unicamente, um processo racional e constante e dependesse, exclusivamente, da aprendizagem acadêmica dos estudantes. Acreditamos que não se pode ignorar as dificuldades individuais e coletivas, os sentimentos, as situações organizacionais e de aprendizagem mobilizadoras de ansiedade. Neste sentido, precisamos de um maior espaço para a informação, discussão, reflexão e, principalmente, a oportunidade para compreensão do fenômeno.

Entendemos que o ensino não deve contribuir com os fatores socioculturais que dificultam a elaboração do luto. Deve fornecer subsídios para o desenvolvimento cognitivo e emocional e as atitudes frente à morte, além de fortalecer a capacidade de elaboração do luto.

Os dados obtidos certamente contribuirão com a elaboração de um conteúdo programático destinado à organização de uma disciplina eletiva sobre a morte e o morrer.

7. Jodelet D. Les reprèsentations sociales. Paris: Presses Universitaires de France; 1989.

8.Conselho Nacional de Saúde. Resolução n. 196, de 10 de outubro de 1996. Diretrizes e normas regulamentadoras de pesquisas em seres humanos. Mundo Saúde. 1996;21(1):52-61.

9. Lüdke M; André M. Pesquisa em educação: abordagens qualitativas. São Paulo: EPU; 1986.

10. Bowlby J. Perda: tristeza e depressão. São Paulo: Martins Fontes; 1985.

11. Cassorla RMS, coordenador. Da morte: estudos brasileiros. $2^{\mathrm{a}}$ ed. Campinas: Papirus; 1998.

12. Stedford E. Encarando a morte: uma abordagem ao relacionamento com o paciente terminal. Porto Alegre: Artes Médicas; 1986. 
13. Klafke TE. O médico lidando com a morte: aspectos da relação médico-paciente terminal em cancerologia. In: Cassorla RMS, coordenador. Da morte: estudos brasileiros. Campinas: Papirus; 1998. p. 25-49.

14. Boemer MR, Rossi LRG, Nastari RR. A idéia de morte em Unidade de Terapia Intensiva: análise de depoimentos. In: Cassorla RMS, coordenador. Da morte: estudos brasileiros. Campinas: Papirus; 1991. p. 145-57.

15. Lunardi Filho WD, Sulzdach RC, Nunes AC, Lunardi VL. Percepções e condutas dos profissionais de Enfermagem frente ao processo de morrer e morte. Texto Contexto Enferm. 2001;10(3):60-81.
16. Ribeiro MC, Baraldi S, Silva MJP. A percepção da equipe de enfermagem em situação de morte: ritual do preparo do corpo pós-morte. Rev Esc Enferm USP. 1998;32(2):117-23.

17. Lunardi VL, Lunardi Filho WD. A morte do idoso: um fato natural e aceitável? Texto Contexto Enferm. 1997;6(2):322-9.

18. Spindola T; Macedo MCS. A morte no hospital e seu significado para os profissionais. Rev Bras Enferm. 1994;47(2):108-17.

19. Cassorla RMS. Reflexões sobre a psicanálise e a morte. In: Kovács MJ, Morato HTP, Rothschild D, Freitas LV, Calazans RA, Cassorla RMS, et al. Morte e desenvolvimento humano. São Paulo: Casa do Psicólogo; 2002. p. 19-112. 